\title{
Shinji Takahashi, M.D. (1912-1985): pioneer in early development toward CT and IMRT
}

\author{
Kunio Doi $\cdot$ Kozo Morita $\cdot$ Sadayuki Sakuma • \\ Masaki Takahashi
}

Published online: 14 October 2011

(C) Japanese Society of Radiological Technology and Japan Society of Medical Physics 2011

Professor Shinji Takahashi (Fig. 1) was born in January 1912 in Nihonmatsu town (currently Nihonmatsu City), Fukushima Prefecture, Japan. He became the First Honorary Citizen of Nihonmatsu City in 1985. He graduated from the Tohoku Imperial University Faculty of Medicine, in Sendai, with an M.D. degree in March 1938 and immediately entered the Radiology Department of the same university for training. He was appointed as a lecturer in the same department in 1942, and in 1947, at the age of only 35 , he moved from Sendai to Hirosaki to take up a post as professor at the Aomori Medical School, which became the Hirosaki University School of Medicine in 1949.

Professor Takahashi had a number of unique accomplishments during his lifetime. His first world-class accomplishment was the development of what was then called "rotation radiography" $[1-3,5]$, the precursor of present-day computed tomography (CT). The term "rotation radiography" was used because the X-ray tube and the film were rotated around the subject to be examined

\author{
K. Doi $(\bowtie)$ \\ Emeritus Professor, Department of Radiology, \\ University of Chicago, Chicago, IL, USA \\ e-mail:k-doi@uchicago.edu \\ K. Doi \\ Gunma Prefectural College of Health Sciences, Maebashi, Japan \\ K. Morita \\ Honorary Director \\ Aichi Cancer Center Hospital, Nagoya, Japan \\ S. Sakuma \\ Emeritus Professor, Nagoya University, Nagoya, Japan \\ M. Takahashi \\ Director, Nagoya Clinical Center, Nagoya, Japan
}

through a certain point. He began this research in 1946, when Japan was overwhelmed by its defeat in World War II, and he attempted various methods of obtaining X-ray images of cross sections of the human body. One method was called direct cross-sectional radiography, which was essentially the same as what later developed into CT. However, it was the fifth method, rotatory cross-sectional radiography, which Professor Takahashi reported in May 1950, and which came to be applied in actual medical practice (Fig. 2). In this method, X-rays continuously irradiated the body at an angle of $15^{\circ}$ toward the cross section to be captured, while the patient, in a standing or sitting position, and a cassette placed horizontally were continuously and synchronously rotated through $190^{\circ}$. Later, a universal rotatography device (Fig. 3) was developed that enabled imaging of cross sections using various methods developed by Professor Takahashi. With this device, the patient did not need to remain in a standing or sitting position, but could be placed in the decubitus position, facilitating stabilization of the patient and also eventually contributing to the development and practical application of conformational radiotherapy.

In 1950, Professor Takahashi reported a solidography method [2] based on that given above in which images were obtained in a manner similar to multisection tomography. Although instability within Japan following the war inhibited the flow of academic information from abroad, Professor Takahashi stated for the first time in "Rotation Radiography" [2], published in 1957, that Vallebona and Gebauer each had reported similar methods-axial transverse stratigraphy and transversale Schichtaufnahmearound the same time, in 1948 and 1949, respectively. Based on these reports, the solidography method later became known internationally as "axial transverse tomography", as shown in Fig. 4. 


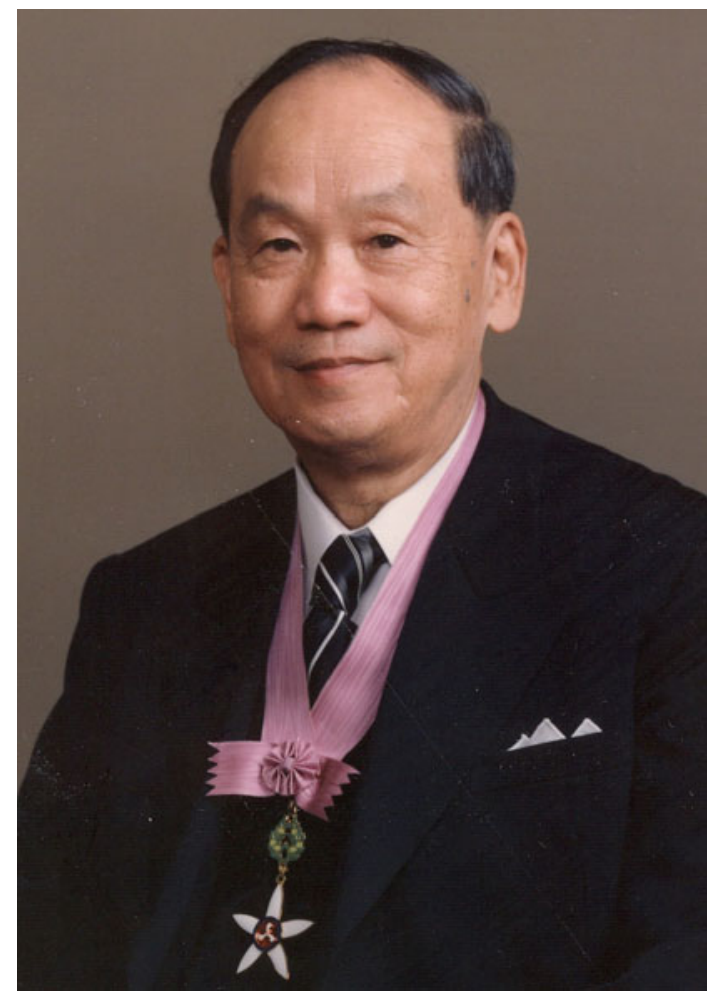

Fig. 1 Portrait of Shinji Takahashi, M.D

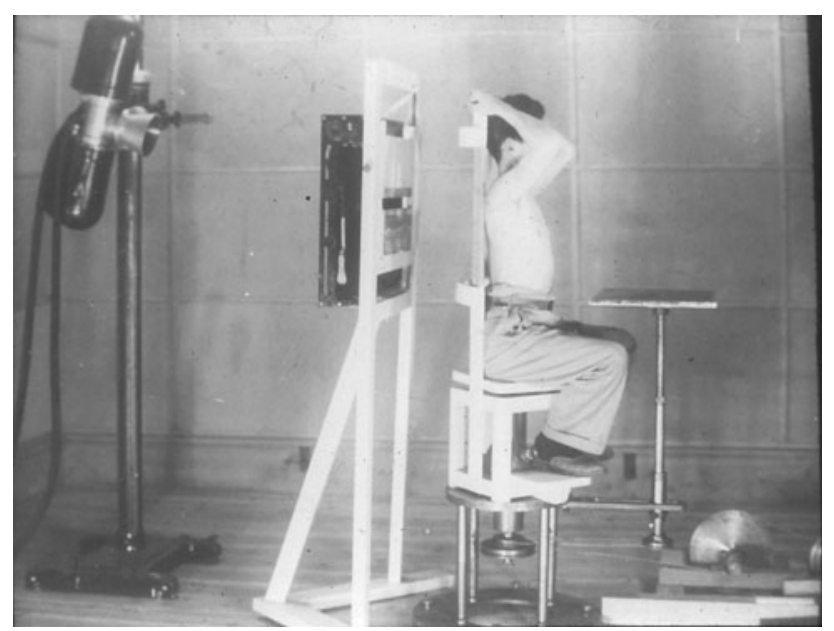

Fig. 2 The first device for rotatory cross-sectional radiography

In his book "Rotation Radiography" [2], Professor Takahshi described in detail the principle of producing a cross-sectional image based on the reconstruction from a sinogram, which was then called "rotatogram" or "rotation radiogram". He obtained sinograms on film by exposing a slit X-ray beam while the subject was rotated. In addition, he was able to explain theoretically and experimentally the relationship between various subject structures in the object plane (cross-sectional plane) and the corresponding

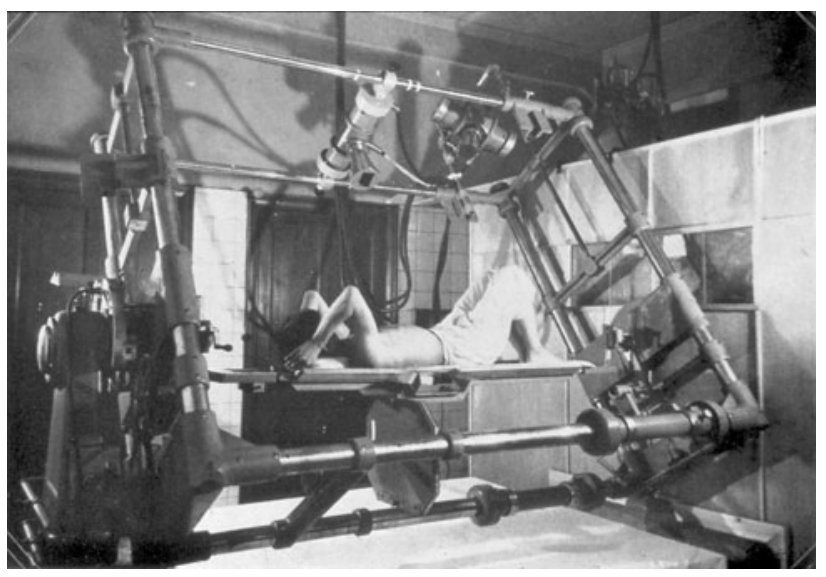

Fig. 3 The first universal rotatography device with the patient in the decubitus position

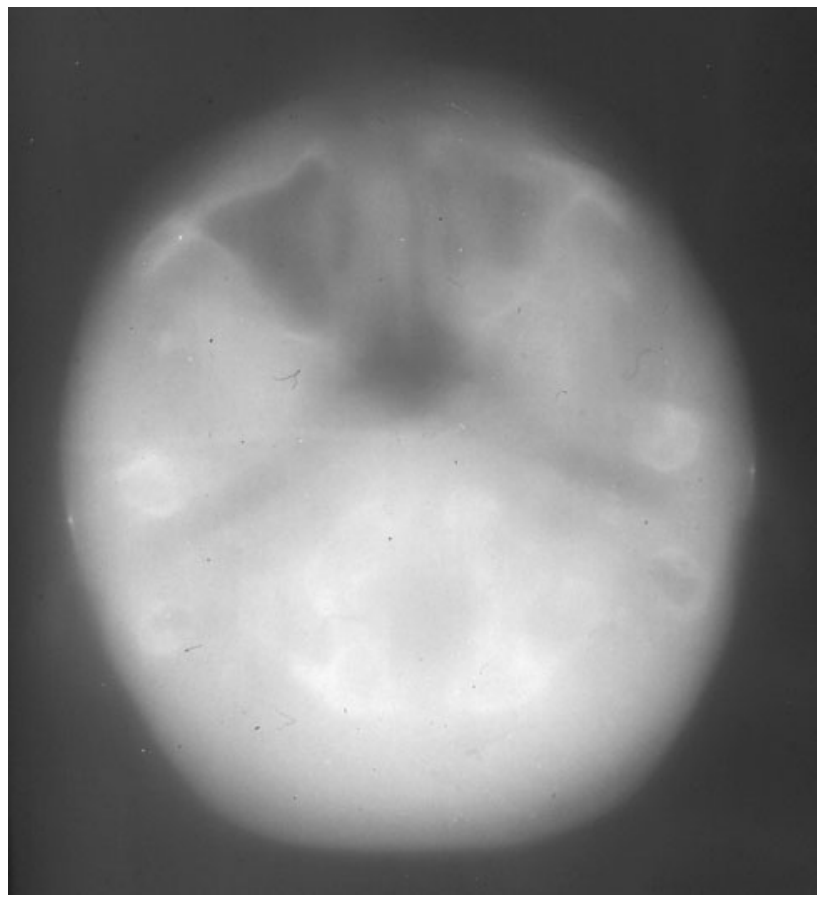

Fig. 4 Axial transverse tomogram of left maxillary sinus carcinoma

sinograms. Professor Takahashi attempted to obtain crosssectional images directly using various devices, and also in two steps by first producing film sinograms (Fig. 5) and then reconstructing the cross-sectional image (Fig. 6) using an analog optical device for back-projection.

It is clear that Professor Takahashi understood the principle of modern CT in the 1950s, long before Godfrey N. Hounsfield reported the development of the first CT images in 1972. Subsequently, in 1979, Hounsfield and Alan M. Cormack were awarded the Nobel Prize for the invention of CT. 


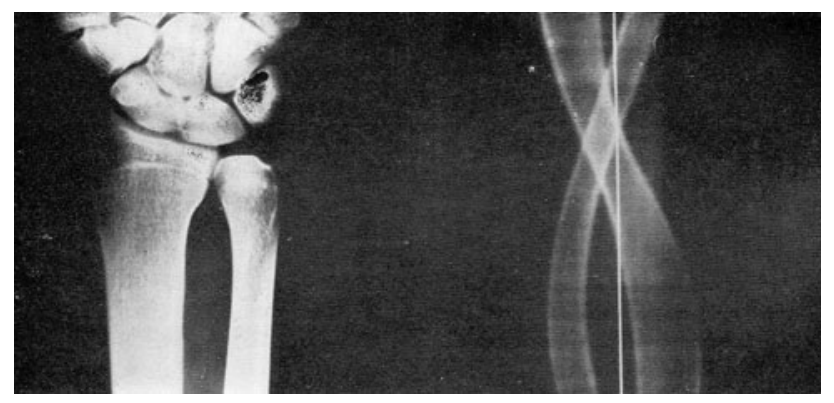

Fig. 5 Normal radiogram of the lower arm (left) and continuous rotatogram (right), which corresponds to sinogram (reproduced from Fig. 31 on page $42[2])$

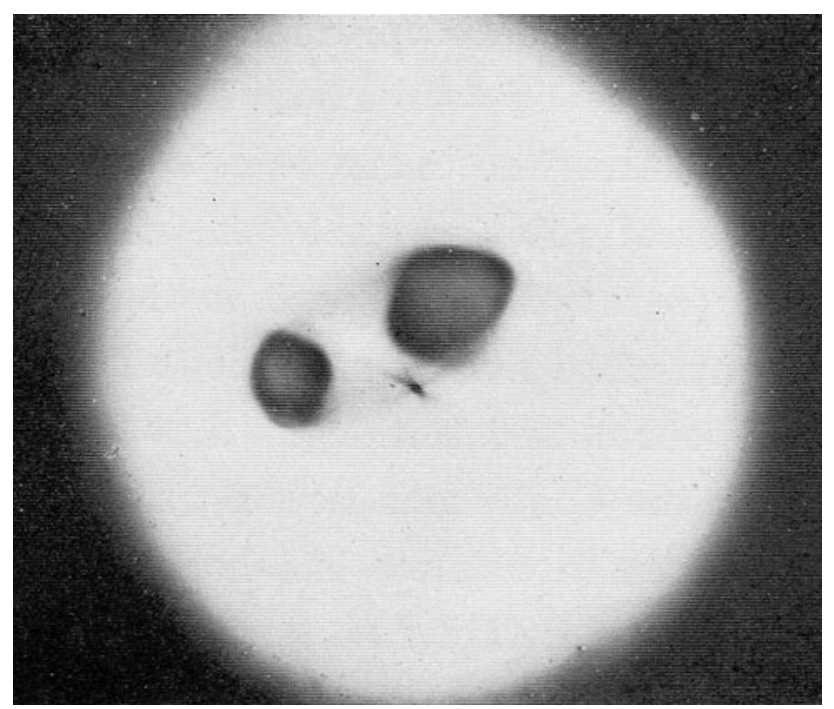

Fig. 6 Reconstructed cross-sectional image obtained from the sinogram shown in Fig. 5 (reproduced from Fig. 32 on page 42 [2])

In 1954, Professor Takahashi was appointed as Professor at the Nagoya University School of Medicine, where he established the Department of Radiology. In 1957, the second rotational Co-60 therapy unit, manufactured in Japan by Shimadzu Corporation, was installed at the Nagoya University. Three years later, in 1960, Professor Takahashi used this unit to develop a method of conformation radiotherapy that was based on rotation radiography and its three-dimensional expansion, solidography, to radiation therapy [4-6]. In this method, the right and left sides of the collimator were multifractionated (multileaf collimator), with each leaf being designed to move independently, and a hollowed-out absorber, obtained with a hollow-out technique, was placed in front of the multileaf collimator to enable the creation of a concave high-dose area (which was called as beam focus) as shown in Fig. 7.

Around the same time, devices for rotation radiography for the decubitus position were already being used

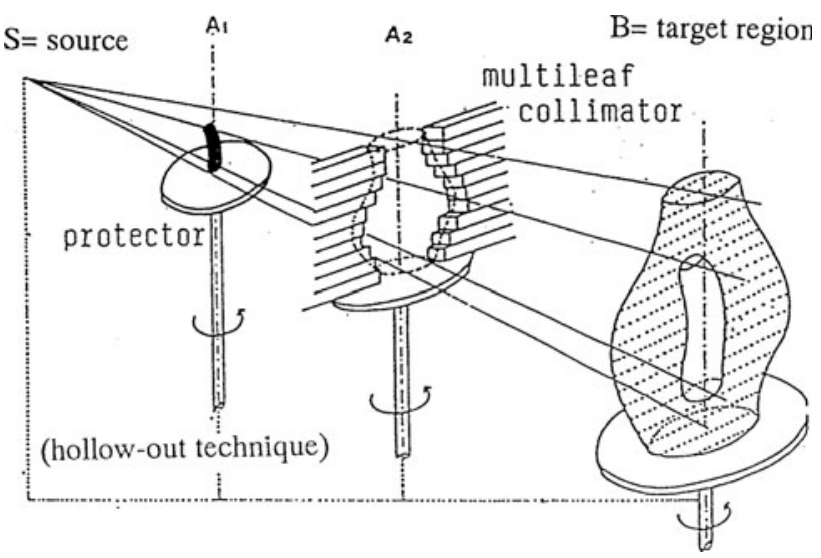

Fig. 7 Principle of conformation radiotherapy by S. Takahashi [5]

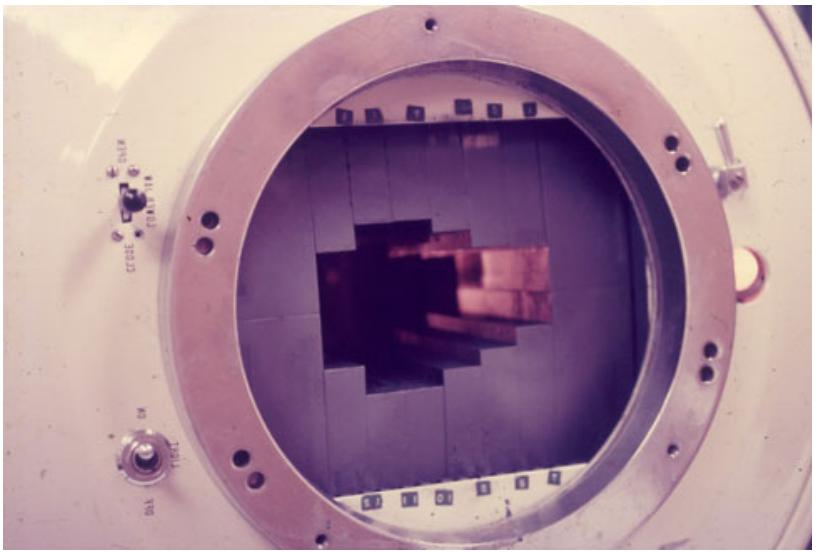

Fig. 8 Multileaf collimator attached to a 6-MV lineac

routinely in planning for radiation therapy. When a threedimensional distribution of a lesion was estimated with the use of these devices, the unit for conformational radiotherapy was then applied to create a high-dose area (beam focus) corresponding to the estimated distribution and shape of the lesion, thereby concentrating radiation to the lesion much more effectively than was possible with previously used techniques. This method was already in use around 1961 for the treatment of cervical, maxillary, esophageal, lung, and other cancers with the use of a rotational Co-60 therapy unit; however, the full application of conformational radiotherapy did not begin until 1967, when a 6-MV linear accelerator at the Aichi Cancer Center became the first in Japan to be equipped with a multileaf collimator (with six leaves each on the right and left sides, one of which corresponded to the 3-cm thickness of the center plane of rotation), as shown in Fig. 8, and a hollowed-out device installed on the outside of the irradiation port (Fig. 9). This unit was used in conformational radiotherapy for various types of cancers.

In the 1980s, rotation radiography devices used for conformational radiotherapy were replaced by $\mathrm{CT}$ devices. 


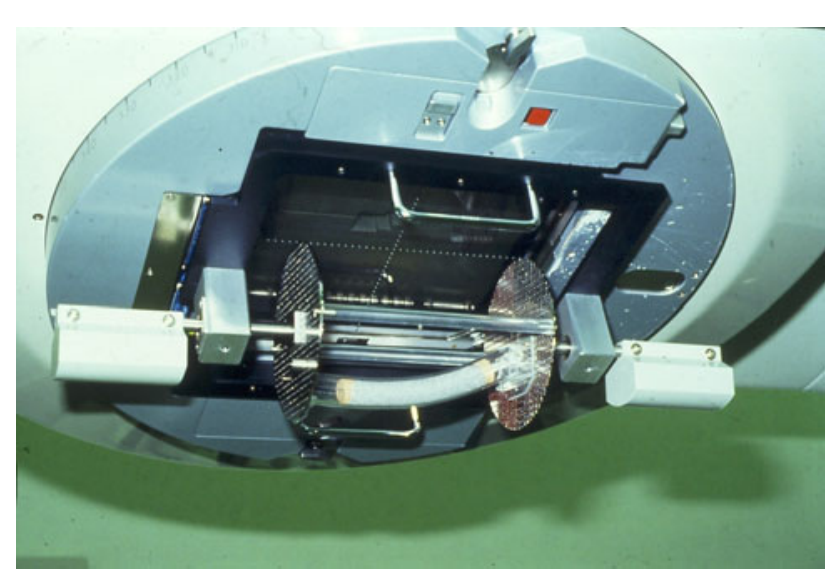

Fig. 9 Device for hollow-out technique

Computerized control systems for multileaf collimators were introduced, and conformational radiotherapy quickly became associated with the advanced computer systems for treatment planning. Moreover, conformational radiotherapy evolved into intensity-modulated radiation therapy (IMRT), which gained widespread use in the 1990s.

In 1977, Professor Takahashi received the 67th Japan Academy Prize and an Imperial Prize for "Study on PathoAnatomical Analysis of the Living Body by Means of X-Rays", for his exploration of magnification radiography in addition to many other achievements described above. For magnification radiography, the focal spot of the X-ray tube needs to be extremely small. Since his time at the Hirosaki University, Professor Takahashi had made a number of attempts to obtain a microfocus X-ray tube. In 1958, after Professor Takahashi had moved to the Nagoya University, a bias-type microfocus rotating-anode X-ray tube with a focal spot size of $50 \mu$ was developed, and it began to be applied in clinical practice. In the application of this X-ray tube, several X-ray tubes with different focalspot sizes were lined up, and magnification radiographs of the same body part were obtained at one to four magnification ratios by moving the examination table horizontally. This method was used for plain radiography of bones and lungs, and also for bronchography. Serial angiography of blood vessels also became possible with the combined use of a device designed to change the cassettes continuously. This research was continued at the Nagoya City University by Professor Sadayuki Sakuma, one of Professor Takahashi's collaborators, and the results were published in 1975 [7].

In 1966, Professor Takahashi became a member of the Committee 3 of the International Commission on Radiological Protection (ICRP), and in 1973 he became a member of the main Commission. The mission of the ICRP is to study the impact of radiation on the global environment and to identify the ways of protecting against such an impact. For the subsequent 15 years, Professor Takahashi contributed to the expansion of the ICRP [8] and fulfilled his duty by always attending the annual committee meetings. To acknowledge Professor Takahashi's contribution to the Commission, the ICRP made him an Honorary Member in 1980, and he organized the ICRP meeting held in Tokyo in May of the following year.

In 1974, Professor Takahashi was appointed Vice President of the newly opened Hamamatsu University School of Medicine. In 1980, he became President of the Aichi Cancer Center. In 1984, he was awarded the Order of Culture by the Japanese Government for his numerous achievements in radiology.

In March 1985, Professor Takahashi retired as the President of the Aichi Cancer Center, and he passed away from pancreatic cancer in April. He was 73 years old. In July of the same year, he was posthumously awarded the Gold Medal of the Royal Swedish Academy of Sciences.

\section{References}

1. Takahashi S, Imaoka M, Shinozaki T. Rotating crossgraphy (study on the rotatography 13th report). Nippon Acta Radiologica. 1950;10:1-8.

2. Takahashi S. Rotation radiography. Tokyo: Japan Society for the Promotion of Science; 1957. p. 1-164. http://www.jsrt.or.jp/web_ data/historicalrecord/rpt_takahashi_simple.pdf

3. Takahashi S, Shinozaki T. Solidography-multisection rotation radiography of the heart and the model of the heart imaged on the serial rotation radiograms (study on the solidography 1st report) (study on the rotatography 22nd report). Nippon Acta Radiologica. 1958;13:479-84.

4. Takahashi S. A new device of Co-60 rotation therapy. Clin Radiol (Tokyo). 1960;5:653-8.

5. Takahashi S. Conformation radiotherapy rotation techniques as applied to radiography and radiotherapy of cancer. Acta Radiol Suppl. 1965;242:1-142.

6. Takahashi S, Koga S, Kato HT. Der Rotatograph für transversale Schichtaufnahmen am liegenden Patienten. Der Radiologe. 1969;9:49-53.

7. Takahashi S, Sakuma S. Magnification radiography. Berlin: Springer; 1975.

8. Takahashi S. Spirit of ICRP (lecture at Hamamatsu Medical University on November 23rd, 1979). Takahashi Shinji Memorial Lectures Series 1. The Medical Radiation Protection Association; 1999. p. 11-7.

Kunio Doi, Ph.D., Editor-in-Chief

Kozo Morita, M.D., Honorary Director

Sadayuki Sakuma, M.D., Emeritus Professor

Masaki Takahashi, M.D., Director 